\title{
PENGARUH SENAM JANTUNG TERHADAP PENURUNAN TEKANAN DARAH PADA LANSIA PENDERITA HIPERTENSI DI UPT PUSKESMAS HELVETIA MEDAN 2020
}

\author{
${ }^{1}$ Refor Arniati Baeha, ${ }^{2}$ Baskara Lumban Tobing, ${ }^{3}$ Berkat Jaya Waruwu, ${ }^{4}$ Christopher Abdi Putra \\ Zebua, ${ }^{5}$ Tiarnida Nababan \\ 1,2,3,4,5 Program Studi S-1 Keperawatan, Universitas Prima Indonesia, Indonesia \\ Email: 1reforarniatibaeha@gmail.com, ${ }^{2}$ baskaratobing04@gmail.com, \\ 33erkatjayawaruwu@gmail.com, ${ }^{4}$ christopher.abdiputra@gmai.com, ${ }^{5}$ tiarnidan@yahoo.com
}

\begin{abstract}
ABSTRAK
Hipertensi atau yang sering dikenal dengan tekanan darah tinggi ialah suatu keadaan yang dimana terjadi tekanan pada pembuluh darah yang meningkat secara bertahap. Tekanan darah tinggi juga suatu masalah yang terjadi pada pembuluh darah dan dapat mengakibatkan terganggunya suplai oksigen. Tujuan umum dari penelitian ini untuk mengetahui Pengaruh Senam Jantung Terhadap Penurunan Tekanan Darah Pada Lansia Penderita Hipertensi di UPT Puskesmas Helvetia Medan 2020. Jenis penelitian ini menggunakan quasi experimental study without control grup. Lokasi penelitian ini dilakukan di UPT Puskesmas Helvetia Jl. Matahari Raya No. 47, Helvetia Tengah, Kec. Medan Helvetia, Kota Medan, Sumatra Utara. Waktu Penelitian Penelitian ini dilaksanakan pada bulan Januari 2020 dengan jumlah sampel 20 orang, instrumen penelitiannya yaitu dengan melakukan wawancara langsung kepada pasien. Nilail dari uji Wilocoxon Signedr Rank Test pretest dan posttest didapatkan hasil dari tekanan darah diastole yaitu nilai $Z$ sebesar 3.961 dengan p-value sebesar 0,000. Dari nilai uji p-value lebih kecil dari 0,05 (0,000<0,05). Sehingga dapat kita artikan bahwa Ho ditolak sehingga terdapat perbedaan antara tekanan diastole pre test dan post test. Kesimpulan ada pengaruh senam jantung terhadap penurunan tekanan darah pada lansia penderita hipertensi di UPT Puskesmas Helvetia Medan tahun 2020.
\end{abstract}

Kata Kunci : Hipertensi, Senam Jantung, dan Lansia.

\section{ABSTRACT}

Hypertension or what is often known as high blood pressure is a condition in which the pressure in the blood vessels increases gradually. High blood pressure is also a problem that occurs in blood vessels and can result in disruption of oxygen supply. The general objective of this study was to determine the effect of cardiac exercise on reducing blood pressure in elderly people with hypertension at the UPT Puskesmas Helvetia Medan 2020. This type of research uses a quasi experimental study without a control group. The location of this research was conducted at UPT Puskesmas Helvetia Jl. Matahari Raya No. 47, Central Helvetia, Kec. Medan Helvetia, Medan City, North Sumatra. Research Time This research was conducted in January 2020 with a sample size of 20 people, the research instrument was by conducting direct interviews with patients. Nilail from the Wilocoxon Signedr Rank Test pretest and posttest obtained results from diastolic blood pressure, namely a $Z$ value of 3.961 with a p-value of 0.000 . From the test value the p-value is less than $0.05(0.000<0.05)$. So that we can mean that Ho is rejected so that there is a difference between the pre-test and post-test diastolic pressures. In conclusion, there is an effect of heart exercise on lowering blood pressure in elderly people with hypertension at the Helvetia Medan Health Center in 2020.

Keywords: Hypertension, Heart Gymnastics, and the Elderly.

\section{PENDAHULUAN}

World Health Organization (WHO) mengatakan bahwa setiap negara penyakit hipertensi merupakan penyebab kematian nomor 1 di dunia dan yang sering kita jumpai. Dan tidak tertutup kemungkinan akan terus meningkat tiap tahunnya penderita hipertensi seiring bertambahnya jumlah masyarakatnya. Pada tahun 2025 yang akan datang dipastikan sebanyak 1 milliar orang penderita hipertensi $33,3 \%$ berada dinegara maju dan sisanya $66,7 \%$ berada didaerah berkembang salah satunya Indonesia (Kementrian Kesehatan RI, 2012). 
Hipertensi atau yang sering dikenal dengan tekanan darah tinggi ialah suatu keadaan yang dimana terjadi tekanan pada pembuluh darah yang meningkat secara bertahap (World Health Organization, 2018). Tekanan darah tinggi juga suatu masalah yang terjadi pada pembuluh darah dan dapat mengakibatkan terganggunya suplai oksigen. Akibatnya tekanan darah diarteri bekerja lebih keras sehingga jantung juga semakin memaksa bekerja memenuhi kebutuhan tersebut. Faktor- faktor yang menyebabkan terjadinya hipertensi pada lansia ialah usia, jenis kelamin, genetic, obesitas, kebiasaan merokok, konsumsi garam dan stress.

Data Riskesdas tahun 2018 prevalensi hipertensi di Indonesia mulai pada umur lebih dari 18 tahun meningkat drastis sebesar $34,1 \%$. Sebelumnya data dari Riskesdas tahun 2013 prevalensi hipertensi sekitar $25,8 \%$. Dari data tersebut kita ketahui dari tahun ketahun jumlah penderita hipertensi terus meningkat.

Hipertensi juga telah masuk kategori 10 penyakit terbesar diseluruh Kota Medan. Dari Dinas Kesehatan Provinsi Sumatra Utara, terdapat 50.162 orang mengidap penyakit Hipertensi. Dari data tersebut didapat jumlah yang terbanyak menderita hipertensi ialah wanita sebanyak 27.021 dan diusia mulai dari 55 tahun keatas. Dan yang paling sering dialami oleh lansia dikarenakan adanya gangguan sirkulasi darah (Azizah, 2011).

Menurut data WHO kelompok lansia umur 60 tahun keatas merupakan kelompok umur yang telah memasuki tahapan akhir dari fase hidupnya. Adapun jenjang dikatakan lansia usia pertengahan (middle age) dari umur 45 sampai 59, usia lanjut (elderly) dari umur 60 sampai 74 tahun, lanjut usia tua (old) dari umur 75 sampai 90 tahun dan usia sangat tua (very old) diatas usia 90 tahun.

Tekanan darah dapat diturunkan dengan olahraga teratur karena dapat melancarkan peredaran darah pada arteri tanpa mengkonsumsi terapi farmakologi (Marssy, 2007). Penderita tekanan darah tinggi dianjurkan untuk sering melakukan aktivitas fisik salah satunya seperti senam jantung. Senam jantung jika dilakukan secara rutin akan meningkatkan fungsi jantung dan dapat menurunkan tekanan darah dan juga dapat mengurangi penumpukan lemak yang terdapat pada dinding dinding pembuluh darah (Nugroho, 2008).

Senam jantung ialah suatu kegiatan ataupun latihan fisik yang mengutamakan kemampuan jantung, serta menggerakkan seluruh otot dan juga kelenturan sendi sendi serta meningkatkan pemasukkan oksigen keotot-otot terkhusus otot jantung. Dan juga bermanfaat untuk meningkatkan stamina serta fungsi fungsi tubuh seperti jantung, pembuluh darah dan otot serta saluran pernapasan. (Senam Jantung Sehat Seri I, 2003).

Berdasarkan penelitian yang dilakukan oleh (Totok, dkk, 2017) di salah satu panti yang terdapat Kelurahan Pajang Surakarta didapatkan hasil selama 4 kali dalam 2 minggu melakukan senam, ada pengaruh senam jantung terhadap penurunan tekanan darah. Dan juga berdasarkan penelitian yang dilakukan oleh (Amiruddin dkk, 2018) didapatkan hasil bahwa selama frekuensi 5 kali dalam 1 minggu dengan perlakuan 4 minggu dilakukan senam, ada pengaruh senam jantung terhadap penurunan tekanan darah.

Data hasil survey awal yang dilakukan oleh peneliti pada bulan Desember tahun 2019, didapat data dari rekam medik di UPT Puskesmas Helvetia Medan mulai dari bulan November sampai Desember dengan umur 60 tahun keatas sebanyak 68 orang. Pasien yang tidak mengkonsumsi terapi farmakologi terdiri dari 20 orang.Diantaranya pria ada 2 jiwa dan wanita 18 jiwa dengan rata-rata tekanan darah diatas 140/90 $\mathrm{mmHg}$.

Berdasarkan hal tersebut peneliti tertarik untuk melakukan penelitian mengenai pengaruh senam jantung terhadap penurunan tekanan darah pada lansia penderita hipertensi di UPT Puskesmas Helvetia Medan Tahun 2020.

\section{METODE PENELITIAN}

Jenis Penelitian ini menggunakan penelitian quasi experimental study without control grup. Populasi adalah keseluruhan / sekumpulan subjek ataupun objek penelitian yang diteliti secara keseluruhan (Notoatmojo, 2017). Populasi dalam penelitian ini ialah pasien lanjut usia yang mempunyai riwayat darah tinggi dan sama sekali tidak konsumsi obat penurun tekanan darah dengan jumlah populasi sebanyak 20 orang di UPT 
Puskesmas Helvetia Medan terhitung dari bulan November 2019.

Sampel adalah objek yang diteliti dan dianggap mewakili seluruh populasi (Notoatmojo, 2017). Sampel penelitian ini adalah lansia penderita hipertensi yang tidak mengkonsumsi obat penurun tekanan darah di UPT Puskesmas Helvetia Medan sebanyak 20 orang. Karena jumlah populasi kurang dari 30 orang maka teknik pengambilan sampel yaitu memakai Teknik Total Sampling, dan tidak memakai kriteria inklusi dan ekslusi yang artinya seluruh kelompok harus menjadi responden (Jiwantoro, 2017).

Hasil tersebut menggunakan data primer dan sekunder dengan data primer didapat langsung dari klien pada saat melakukan penelitian. Sedangkan data sekunder didapat dari instansi tempat penelitian dengan menggunakan lembaran observasi.

Dengan intervensi yang dilakukan oleh peneliti yaitu memberikan senam selama 4 kali dalam seminggu selama 1 bulan dengan durasi 15 menit di UPT Puskesmas Helvetia Medan. Sebelum dilakukan senam peneliti mengukur tekanan darah terlebih dahulu, dan setelah dilakukan senam peneliti menunggu 20 menit baru mengukur kembali tekanan darah untuk mendapat hasil adanya pengaruh senam terhadap penurunan hipertensi.

Analisa dalam hal tersebut ini menggunakan analisa univariat dan analisa bivariat. Dalam penelitian tersebut univariat memaparkan suatu distribusi frekuensi dari objek persaamaan klien dalam melakukan senam jantung (Pre-test dan Post-test). Analisa bivariat dalam penelitian ini memperlihatkan ada atau tidaknya pengaruh antara variabel independen dan variabel dependen. Dengan menggunakan uji Paired $T$-test jika data tersebut berdistribusi normal maka peneliti menggunkan uji tersebut. Tetapi karena data tidak berdistribusi dengan normal maka peneliti menggunakan uji Wilcoxom Sign Rank Test. Nilai $p \leq 0,05$ maka Ho ditolak dan $\mathrm{Ha}$ diterima menunjukkan adanya pengaruh antara variabel independen dan dependen sementara jika $p \geq 0,05$ maka Ho diterima Ha ditolak menunjukkan bahwa tidak terdapat pengaruh antara variabel independen dan variabel dependen. Setelah itu hasil penelitian dilanjutkan dalam bentuk tabel dan dibahas dengan menggunakan teori yang tersedia.

\section{HASIL DAN PEMBAHASAN}

3.1 Hasil

Analisa Univariat

Berdasarkan hasil Senam Jantung Terhadap Penurunan Tekanan Darah di UPT Puskesmas Helvetia Medan Tahun 2020 maka diperoleh hasil sebagai berikut.

Tabel 1. Karakteristik Distribusi Frekuensi Responden Berdasarkan Jenis Kelamin dan Umur di UPT Puskesmas Helvetia Medan Tahun 2020

\begin{tabular}{|c|c|c|c|}
\hline No & Karakteristik & Frekuensi & $\begin{array}{c}\text { Persentase } \\
(\%)\end{array}$ \\
\hline \multicolumn{4}{|c|}{$1 \quad$ Jenis Kelamin } \\
\hline & a. Laki-laki & 2 & $10 \%$ \\
\hline & b. Perempuan & 18 & $90 \%$ \\
\hline & Umur & & \\
\hline & a. $62-72$ & 11 & $55 \%$ \\
\hline & b. $73-83$ & 9 & $45 \%$ \\
\hline & Total & 20 & $100 \%$ \\
\hline
\end{tabular}

(Sumber Data Primer,2020)

Tabel 2. Distribusi Responden BerdasarkanHasil Penelitian Sebelum Dan Sesudah Dilakukan Senam Jantung di UPT

Puskesmas Helvetia Medan Tahun 2020 Responden Tekanan Darah Tekanan Darah Sistolik Diastolik

\begin{tabular}{|c|c|c|c|c|}
\hline & Pretest & Posttest & Pretest & Posttest \\
\hline Median & 170.00 & 140.00 & 100.00 & 80.00 \\
\hline
\end{tabular}

Dari tabel 2 diketahui dari hasil penelitian sebelum dan sesudah dilakukan senam jantung diperoleh nilai rat-rata tekanan darah sistolik sebelum dilakukan senam jantung adalah $(166.50 \mathrm{mmHg})$ dan setelah dilakukan senam jantung didapat hasil ratarata $(137.50 \mathrm{mmHg})$. Setelah itu nilai dari tekanan darah diastolik sebelum dilakukan senam jantung rata-rata adalah (104.00 $\mathrm{mmHg}$ ) dan selesai dilakukan senam jantung didapat nilai rata-rata $(79.00 \mathrm{mmHg})$.

Berdasarkan tabel 1 dari data karakteristik jenis kelamin responden diatas diperoleh yang lebih dominan yaitu perempuan 18 responden (90\%). Berdasarkan dari data karakteristik umur diatas diperoleh dengan rentang 62-72 tahun berjumlah 11 responden $(55 \%)$.

Dari hasil uji normalitas dengan menggunakan metode Shapiro-Wilk dimana data diatas tidak berdistribusi normal 
sehingga tidak bisa menggunakan uji t-test atau bagian dari analisis statistik parametik untuk mengkaji data. Sehingga harus menggunakan uji alternatif salah satunya ialah uji Wilcoxon Signed Rank Test atau uji nonparametik karena tingkat keberhasilan $95 \%$.

Tabel 3. Perbandingan Hasil Uji Wilcoxon Signed Rank Test Sebelum Dan Sesudah Dilakukan Senam Jantung di UPT Puskesmas Helvetia Medan 2020

\begin{tabular}{lccccc}
\hline Variabel & \multicolumn{2}{c}{$\mathrm{X} \pm$ SD } & $\mathrm{Z}$ & $p$ value & Keputusan \\
\cline { 2 - 5 } & Pre-Test & Post-Test & & & \\
\hline Sistol & $\mathbf{1 6 6 . 5 0} \pm \mathbf{8 . 1 2 7}$ & $\mathbf{1 3 7 . 5 0} \pm \mathbf{1 1 . 6 4 2}$ & $\mathbf{3 . 9 7 2}$ & $\mathbf{0 . 0 0 0}$ & Ho ditolak \\
\hline Diastol & $\mathbf{1 0 4 . 0 0} \pm \mathbf{1 2 . 3 1 2}$ & $\mathbf{7 9 . 0 0} \pm \mathbf{9 . 6 7 9}$ & $\mathbf{3 . 9 6 1}$ & $\mathbf{0 . 0 0 0}$ & Ho ditolak \\
\hline
\end{tabular}

Berdasarkan hasil dari uji Wilcoxon Signed Rank Test pre test dan post test didapatkan hasil dari tekanan darah sistol dengan nilai $\mathrm{Z}$ senilai 3.972 dengan nilai $p$ value sebesar 0,000 . Dari nilai uji $p$-value $0,000<0,05$. Sehingga dapat kita artikan bahwa Ho ditolak, terdapat perbedaan antara tekanan darah sistol pre test dan post test.

\subsection{Pembahasan}

Pembahasan dalam hal ini menjelaskan hasil penelitian mengenai Pengaruh Senam Jantung Terhadap Penurunan Tekanan Darah Pada Lansia Penderita Hipertensi di UPT Puskesmas Helvetia Medan Tahun 2020 dengan 20 responden sebagai sampel. Frekuensi responden dari jenis kelamin menyatakan bahwa lebih menunjukan banyaknya responden berjenis kelamin perempuan dengan jumlah responden 18 (90\%). Sedangkan usia responden penderita hipertensi di wilayah UPT Puskesmas Helvetia Medan didapatkan hasil lebih banyak dari usia 62-72 tahun sebanyak 11 lansia $(55 \%)$.

Berdasarkan hasil uji statistik menunjukkan $\rho=0,000 \quad(<\alpha=0,05)$ sehingga dapat disimpulkan bahwa ada pengaruh senam jantung terhadap tekanan darah lansia hipertensi. Hal ini berarti setelah melakukan senam jantung, tekanan darah lansia mengalami penurunan dibandingkan sebelum melakukan senam jantung. Hasil penelitian ini sesuai dengan teori (Sylvia, 2003), bahwa senam jantung adalah olahraga yang disusun dengan selalu mengutamakan kemampuan jantung, gerakan otot besar, dan kelenturan sendi, serta memasukkan oksigen sebanyak mungkin. Selain meningkatnya perasaan sehat dan kemampuan untuk mengatasi stress keuntungan lain dari senam jantung yang teratur adalah menurunnya tekanan darah, berkurangnya obesitas, berkurangnya frekuensi saat istirahat dan menurunnya resistensi insulin. Hasil penelitian ini sejalan dengan penelitian yang dilakukan dengan (Liza, 2015) kegiatan dilakukan selama empat minggu pada 15 orang lansia dengan hipertensi ringan sampai sedang, dari 15 responden melaksanakan senam hipertensi lansia selama 1x seminggu dengan durasi \pm 30 menit. Sebelum melakukan senam jantung rata-rata tekanan darah sistolik lansia hipertensi adalah $145,33 \mathrm{mmHg}$, rata-rata tekanan darah diastolik adalah $88,00 \mathrm{mmHg}$. Setelah melakukan senam hipertensi lansia sebagian besar responden mempunyai tekanan darah pre hipertensi dimana rata-rata tekanan darah sistolik adalah $137,33 \mathrm{mmHg}$, rata-rata tekanan darah diastolik adalah 82,00 $\mathrm{mmHg}$. Analisa senam hipertensi lansia sesuai dengan teori yang dikemukakan oleh (Maryam, 2008) pada usia lanjut kekuatan mesin pompa jantung berkurang. Berbagai pembuluh darah penting khusus di jantung dan di otak mengalami kekakuan. Dengan latihan fisik atau senam dapat membantu kekuatan pompa jantung bertambah karena otot jantung pada orang yang rutin berolahraga sangat kuat sehingga otot jantung pada individu tersebut berkontaksi lebih sedikit dari pada otot jantung individu yang jarang berolahraga, karena olahraga dapat menyebabkan penurunan denyut jantung dan olahraga juga akan menurunkan cardiac output, yang akhirnya dapat menurunkan tenanan darah sesuai dengan teori yang

Dari tabel diatas menunjukkan hasil uji normalitas dengan menggunakan metode Shapiro-wilk yang dimana data sistol pre-test memiliki nilai sig $0,004<0,05$ sedangkan diastole pre-test dengan nilai sig $0,006<0,05$ sehingga demikian data tersebut tidak berdistribusi normal. Maka dari itu analisa 
data yang digunakan dalam penelitian ini ialah uji Wilcoxon Signed Rank Test.

Berdasarkan penelitian yang dilakukan oleh (Putu Dyah Asrim, dkk, 2013) dengan judul pengaruh senam lansia terhadap tekanan darah lansia dengan hipertensi pada kelompok senam lansia dibanjar kaja sesetan denpasar selatan pada kelompok yang telah dilakukan intervensi senam lansia didapat hasil nilai $p$-value $0,000<0,05$ sehingga $\mathrm{Ha}$ diterima Ho ditolak.

Senam jantung juga suatu kegiatan ataupun latihan fisik yang mengutamakan kemampuan jantung, serta menggerakkan seluruh otot dan juga kelenturan sendi sendi serta meningkatkan pemasukkan oksigen keotot-otot terkhusus otot jantung. Dan juga bermanfaat untuk meningkatkan stamina serta fungsi fungsi tubuh seperti jantung, pembuluh darah dan otot serta saluran pernapasan. (Senam Jantung Sehat Seri I, 2003). Jika dilakukan dengan teratur maka hasilnya akan baik pada lansia itu sendiri.

Tekanan darah tinggi yang sering dialami oleh responden terjadi karena beberapa faktor salah satunya kurangnya aktifitas seperti olahraga, faktor usia, pengaturan pola hidup yang kurang baik dan genetic (Harrison dkk, 2005). Dari hasil penelitian yang dilakukan oleh (Safitri, 2017) tekanan darah pada lansia dapat terkontrol jika menerapkan kebiasaan melakukan aktifitas fisik seperti senam hipertensi.

Menurut asumsi peneliti penderita hipertensi yang rutin mengikuti senam jantung dapat menurunkan tekanan darahnya, karena dapat membantu meningkatkan aliran darah dan pemasukan oksigen kedalam otototot jantung dan merilekskan pembuluh darah. Senam jantung juga termasuk dalam aktivitas fiskkarena tidak menyebabkan efek samping kepada responden.

\section{KESIMPULAN}

Dari hasil data tersebut dapat disimpulkan bahwa ada Pengaruh Senam Jantung Terhadap Penurunan Tekanan Darah Pada Lansia Penderita Hipertensi di UPT Puskesmas Helvetia Medan tahun 2020.

\section{REFERENCES}

Amiruddin Eso, dkk. 2018. Pengaruh Senam Jantung Sehat terhadap Tekanan Darah Penderita Hipertensi di Wilayah
Kerja Puskesmas Lepo-Lepo.Volume 6 Nomor 1. EISSN: 2443-0218. Fakultas Kedokteran Universitas Halu Oleo.

Azizah. 2011. Keperawatan lanjut usia. Graha Ilmu, Yogyakarta.

Jiwantoro. 2017. Riset Keperawatan.Analisis dan statistic menggunakan SPSS. Jakarta: Mitra Wacana Media, 2017.

Kementrian Kesehatan RI. Profil Kesehatan Indonesia Tahun 2012. Jakarta: EGC.

Liza, Merianti. Wijaya, Krisna. 2015. Pelaksanaan Senam Jantung Sehat Untuk Menurunkan Tekanan Darah Pada Pasien Hipertensi Di Panti Sosial Tresna Wherda Kasih Sayang Ibu Batu Sangkar. Jurnal Stikes Yarsi. Vol 1 Lombok Barat. Tabel: 24.

Marssy, Rad. 2007. Manfaat Olahraga untuk Kesehatan Pembuluh Darah. http://tutorial-kesehatan.co.id/manfaatolahraga-untuk-kesehatan-pembuluhdarah.html. diakses 17 februari 2016.

Notoatmodjo. 2017. Metodologi Penelitian Kesehatan. Jakarta: Rineka Cipta.

Nugroho, W. 2008. Keperawatan gerontik dan geriatr edisi 3. Jakarta: EGC

Putu Dyah Astri, dkk. 2013. Pengaruh Senam Lansia Terhadap Tekanan Darah Lansia Dengan Hipertensi Pada Kelompok Senam Lansia Di Banjar Kaja Sesetan Denpansar Selatan ISSN: 2303-1298 Vol. 1 No.1 Edisi Januari- Juni 2013.

Riset Kesehatan Dasar (Riskesdas) (2018). Badan Penelitian dan Pengembangan Kesehatan Kementerian RI tahun 2018. http://www.depkes.go.id/resources/down load/infoterkini/materi_rakorpop_20 18/Hasil\%20Riskesdas\%202018.pdf Diakses Agustus 2018.

Rikesdas. 2013. Kementrian Kesehatan RI, Badan Penelitian dan Pengembangan Kesehatan Kementrian Kesehatan RI, Jakarta.

Siti Santy Sianipar. dkk. 2018 Pengaruh Senam Jantung Terhadap Tekanan Darah Penderita Hipertensi Di Puskesmas Kayon Kota Palangka Raya Dinamika Kesehatan Vol 9 No.2 Desember 2018.

Sylvia. 2003. Buku ajar Senam Jantung Sehat. Edisi 1. Yogyakarta: Graha Ilmu.

Tolok Hermawan dan Fahrun Nur Rosyid (2017). Pengaruh Senam Hipertensi Lansia Terhadap Penurunan Tekanan 
Jurnal Ilmiah Keperawatan Imelda

Vol. 6, No. 2, September 2020

http://jurnal.uimedan.ac.id/index.php/JURNALKEPERAWATAN e-ISSN 2597-7172, p-ISSN 2442-8108

Darah Lansia Dengan Hipertensi di Wahyu P,. dkk,. 2017. Pengaruh Senam Panti Werdha Dhara Bakti Kelurahan LansiaTerhadap Tekanan Darah Pada Pajang Surakarta, Jurnal Kesehatan, ISSN 1979-7621Vol. 10 No. 1 Juni 2017.

Wahyuningsih Safitri dan Hutari Puji Astuti (2017), Pengaruh Senam Hipertensi Terhadap Penurunan Tekanan Darah Di Puskesmas Rejo, Jurnal Kesmasdaska, Juli 2017. Lansia Penderita Hipertensi di Posyandu Lansia Dusun Banaran 8 Playen Gunungkidul, Skripsi, Mahasiswa PPNPSIK Stikes Aisyiyah Yogyakarta.

World Health Organization. (2018). Diambil kembali daro Global Health Estimates 2016 Death Cause, Age, Sex, by Country and by Region, 2000-2016.

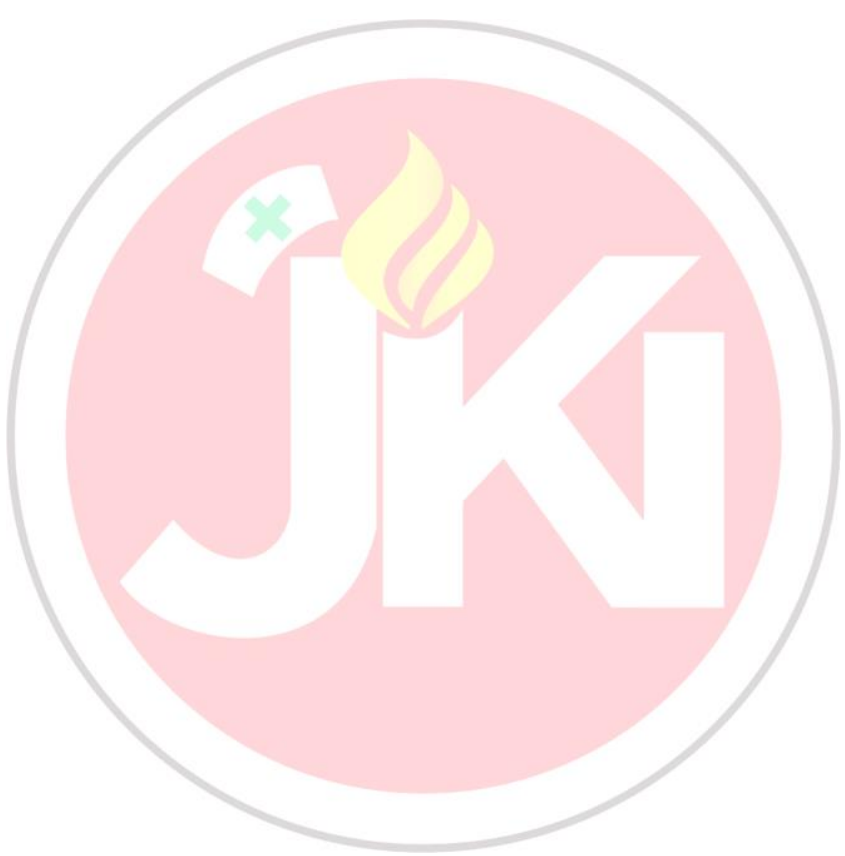

